\title{
Study of Keratomycosis in a Tertiary Care Hospital in Visakhapatnam, India
}

\author{
Venkata Hemalatha Neeli and T. Parvathi* \\ Department of Microbiology, Andhra Medical College, Visakhapatnam \\ *Corresponding author
}

\begin{tabular}{|c|c|}
\hline & A B S T R A C T \\
\hline \multicolumn{2}{|l|}{ Keywords } \\
\hline $\begin{array}{l}\text { Corneal ulcer, } \\
\text { Keratomycosis, } \\
\text { Middle-aged } \\
\text { men, } \\
\text { Trauma, } \\
\text { Vegetative matter. } \\
\end{array}$ & \multirow{3}{*}{$\begin{array}{l}\text { Corneal infections are one of the leading causes of ocular morbidity and } \\
\text { blindness world-wide. If normal defense mechanisms of the eye are } \\
\text { compromised, almost any microorganism can invade the cornea. Fungal } \\
\text { infections affecting the cornea are referred to as keratomycosis or mycotic } \\
\text { keratitis. The peak incidence is seen during harvest seasons particularly in } \\
\text { tropical and sub-tropical environments. Middle-aged men are more } \\
\text { commonly affected. Trauma with vegetative matter serves as the most } \\
\text { important pre-disposing factor for mycotic keratitis. It is important to know } \\
\text { the exact aetiology of corneal ulcer to institute appropriate therapy in time, } \\
\text { lest serious consequences may follow. }\end{array}$} \\
\hline Article Info & \\
\hline $\begin{array}{l}\text { Accepted: } \\
20 \text { March } 2016 \\
\text { Available Online: } \\
10 \text { April } 2016\end{array}$ & \\
\hline
\end{tabular}

\section{Introduction}

Corneal infections are one of the leading causes of ocular morbidity and blindness world-wide (Saha and Das, 2006; Iyer et al., 2006; Upadhyay et al., 1991; Srinivasan, 2004). Most of the pathogens cause ulceration of the cornea; which if not accurately diagnosed in time, may be devastating.

Eyelids, tear film and corneal epithelium serve as normal defense mechanisms against infection. If these are compromised, almost any microorganism can invade the cornea. Among the wide spectrum of cornea invaders, fungi are significant pathogens. Fungal infections affecting the cornea are referred to as keratomycosis or mycotic keratitis. The causative fungi of keratomycosis are ubiquitous.
The peak incidence is seen during harvest seasons particularly in tropical and subtropical environments (Lisa et al., 2011; Wong et al., 1997). Middle-aged men are more commonly affected. Trauma with vegetative matter serves as the most important predisposing factor for mycotickeratitis (Saha and Das, 2006; Lisa et al., 2011; Upadhyay et al., 1991).

It is very important to identify the causative agent of fungal corneal ulcer and institute timely management; lest sight-threatening conditions may follow.

The aim and objectives of this study includes, to isolate and identify the fungi from corneal scrapings of suspected keratitis patients. And 
also to determine their anti-fungal susceptibility pattern.

\section{Materials and Methods}

The present study was conducted at King George Hospital, Visakhapatnam over a period of one year from January 2015 to December 2015. Socio-demographic history and information pertaining to the risk factors was recorded. After diagnosing the infective corneal ulcer clinically, under strict aseptic conditions, corneal scrapings were obtained by qualified ophthalmologists of Regional Eye Hospital, Visakhapatnam and were sent to the Microbiology Department for further processing.

The corneal scrapings were obtained from 50 suspected cases of mycotic keratitis (Figure1) after performing a thorough ocular examination by the slit-lamp bio-microscope. After instillation of $4 \%$ lignocaine eye drops, material from the base and edge of the corneal ulcer was obtained using a sterile Bard-Parker blade (No.15). The sample thus obtained was further processed according to the standard microbiological protocols.

First, direct microscopic examination was done using $10 \% \mathrm{KOH}$ for presumptive diagnosis of mycotic keratitis (Figure 2).

The sample was then inoculated onto Sabouraud's Dextrose Agar (SDA) with Gentamicin and was incubated in a Biological Oxygen Demand (BOD) incubator (Figure
3).Various fungal isolates were obtained (Figure 4 to Figure 9). The isolates obtained were identified and antifungal susceptibility testing was done as per CLSI M44-A2 guidelines for Candida and CLSI M51-A guidelines for non-dermatophytic filamentous fungi.

\section{Results and Discussion}

In the present study, out of 50 corneal scraping samples processed, 15 showed fungal hyphae in $\mathrm{KOH}$ wet mount (Diagram 1).

Out of 50 samples processed, 23 were culture positive for fungal isolates and 27 were culture sterile (Diagram 2).

Filamentous fungi were isolated more when compared to that of yeasts. The various fungal isolates obtained were Aspergillusfumigatus 8 isolates (35\%), A.niger - 5 (22\%), A.flavus 4 (17\%), Pencillium spp. - 2 (9\%), Candida spp. - $2(9 \%)$ and Fusarium spp.- $2(9 \%)$ isolates (Diagram 3).

Fungal corneal ulcers were more common in the age group of 40- 60 years $(56.5 \%)$ followed by $20-40$ years (30\%) (Diagram 4$)$. Thus, economically productive age group is most commonly affected.

Fungal corneal ulcers were more common in the males (65.21\%) when compared to that of females (Diagram 5). This might be because of more occupational exposure of males compared to that of females.

Table.1 Anti-fungal susceptibility testing for fungal isolates isolated from corneal ulcers

\begin{tabular}{|c|c|c|c|}
\hline & Susceptible & Intermediate & Resistant \\
\hline Amphotericin-B & $34.78 \%$ & $43.47 \%$ & $21.73 \%$ \\
\hline Itraconazole & $43.47 \%$ & $13.04 \%$ & $43.47 \%$ \\
\hline Fluconazole & $17.39 \%$ & $30.43 \%$ & $52.17 \%$ \\
\hline Ketoconazole & $30.43 \%$ & $21.73 \%$ & $47.82 \%$ \\
\hline Clotrimazole & $26.08 \%$ & $30.43 \%$ & $43.47 \%$ \\
\hline Nystatin & $13.04 \%$ & $52.17 \%$ & $34.78 \%$ \\
\hline
\end{tabular}


Figure.1 Clinical Photographs Showing Typical Corneal Ulceration

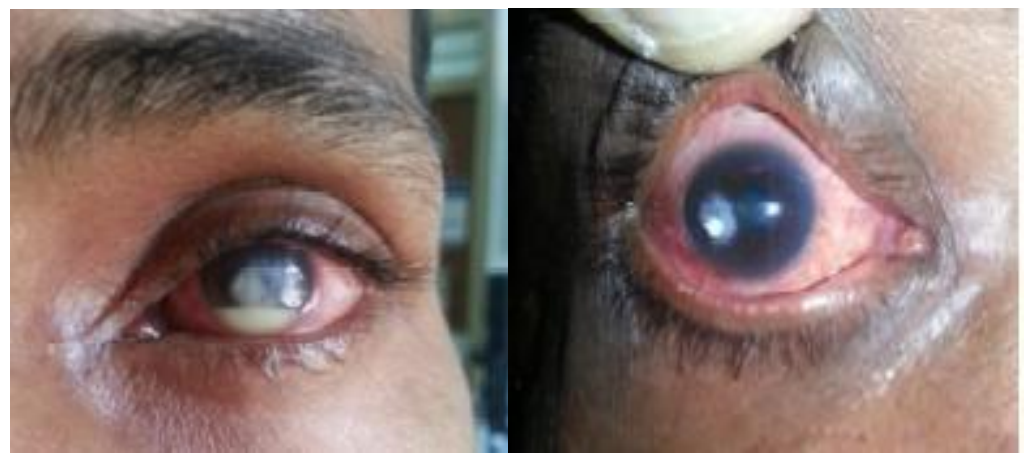

Figure.2 KOH Mount Showing Septate Hyphae

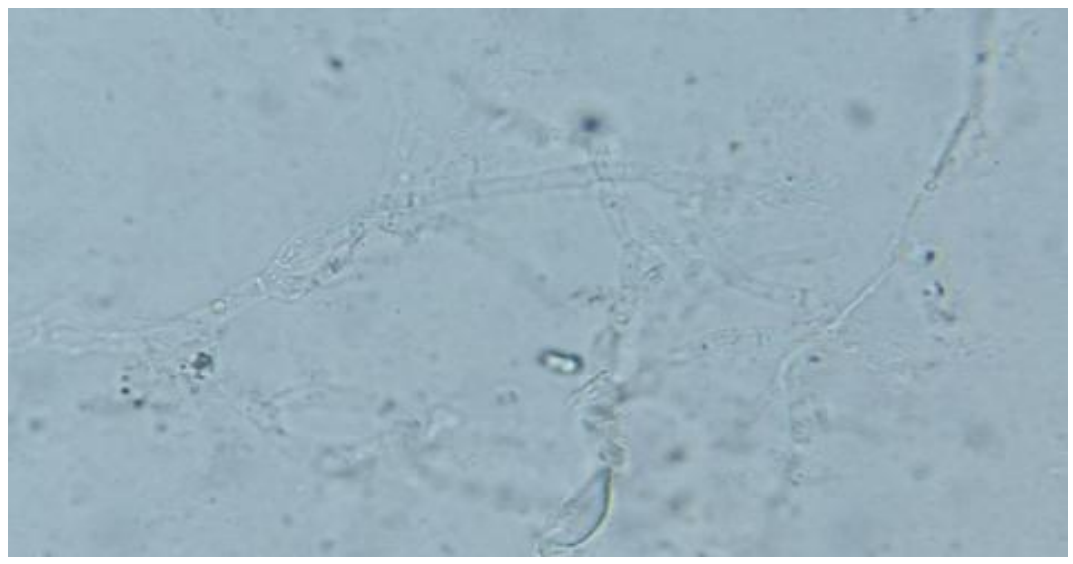

Figure.3 BOD Incubator with McCartney Bottles Showing Fungal Colonies on SDA

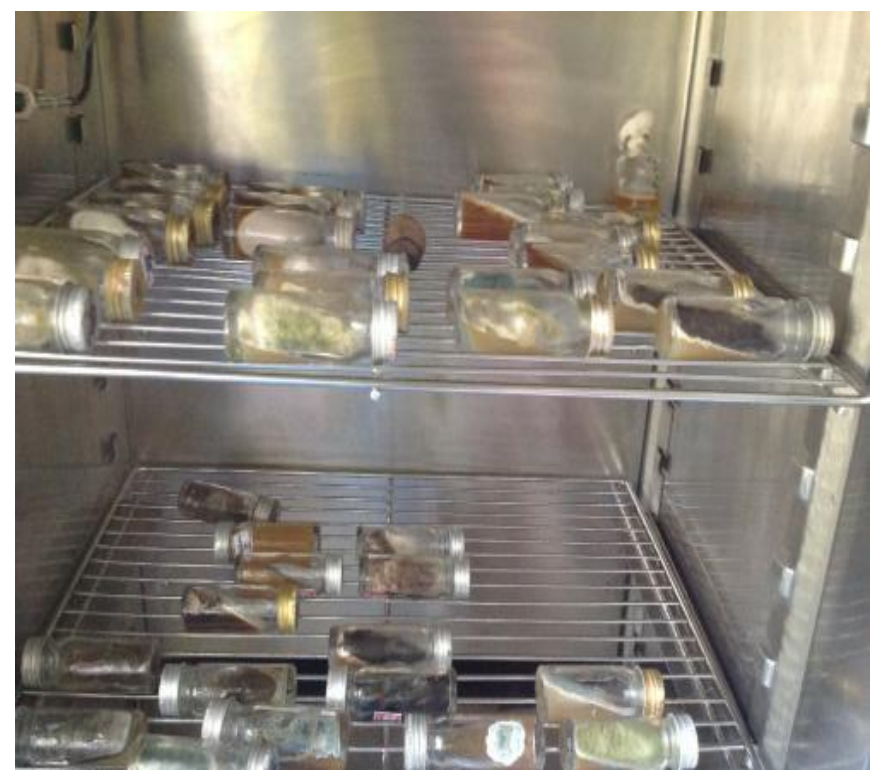


Figure.4 SDA and LPCB Wet Mount Showing Fusarium spp

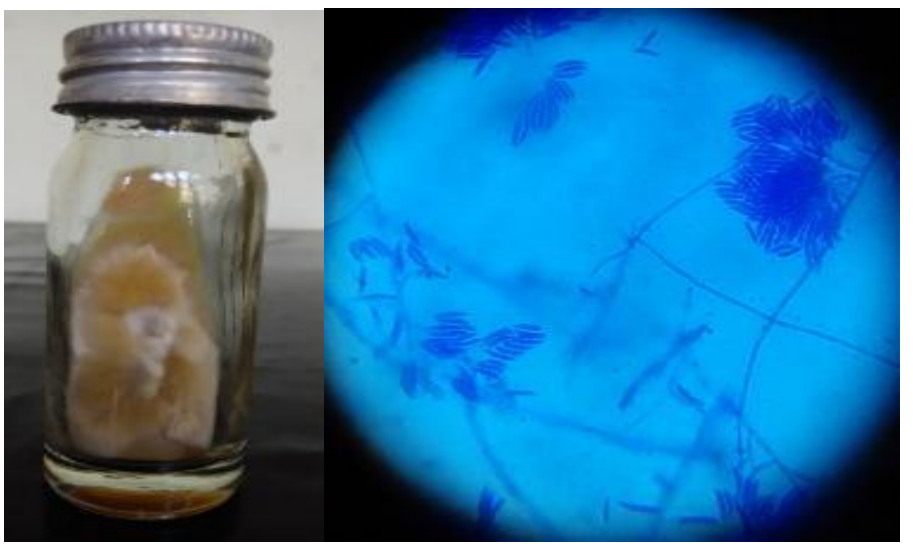

Figure.5 SDA and LPCB Wet Mount Showing Aspergillus flavus

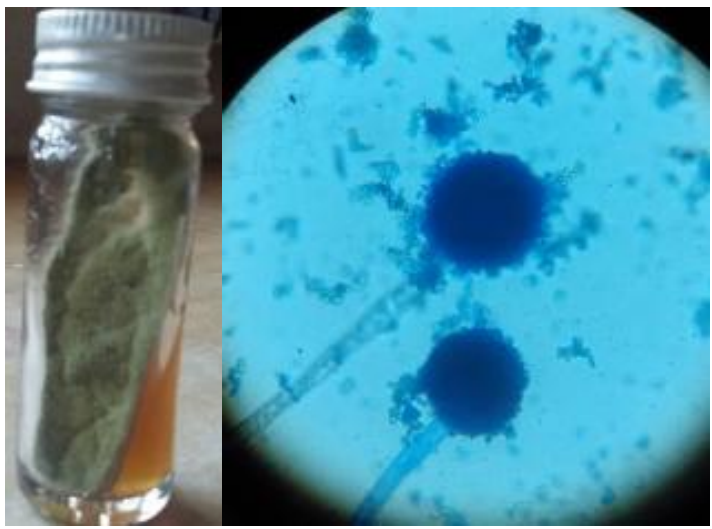

Figure.6 SDA and LPCB Wet Mount Showing Aspergillus niger

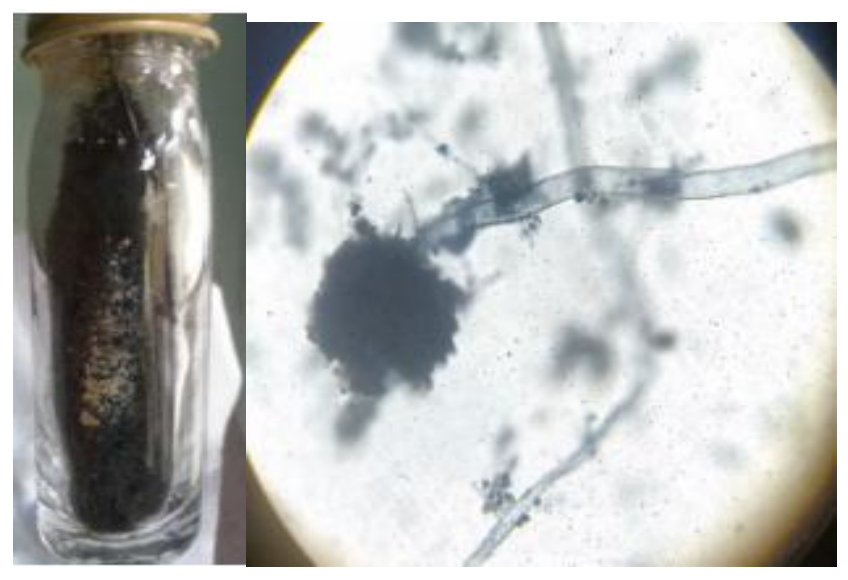


Figure.7 SDA and LPCB Wet Mount Showing Aspergillus fumigatus

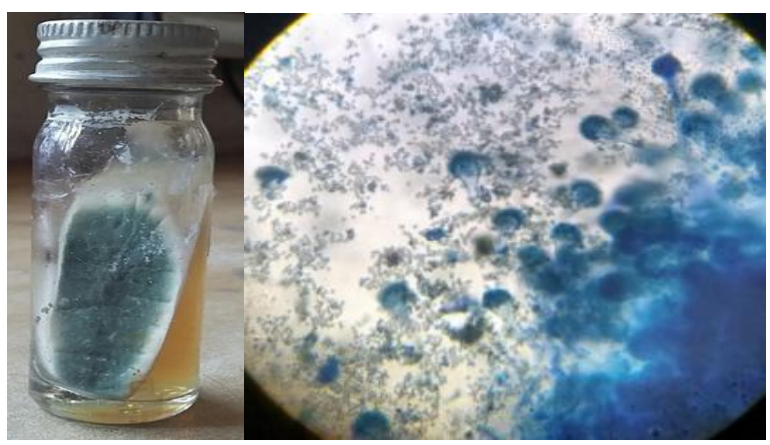

Figure.8 SDA and Gram's Stain Showing Candida spp

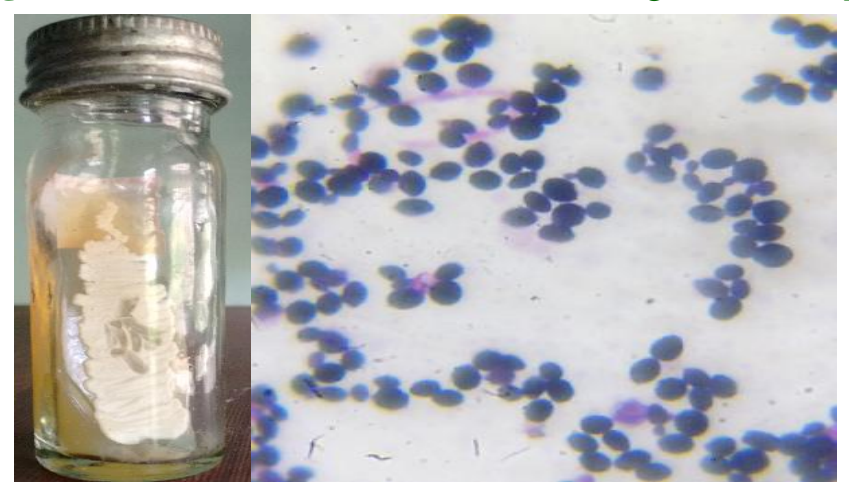

Figure.9 SDA and LPCB Wet Mount Showing Pencillium spp

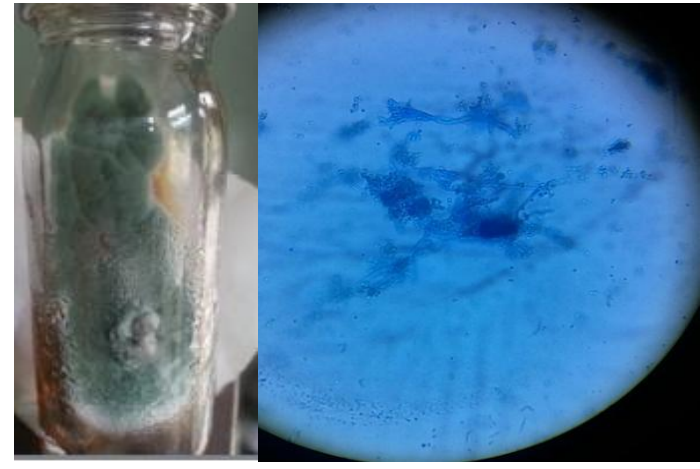

Diagram.1 Pie Diagram Representing percentage of Samples Showing Hyphae in $\mathrm{KOH}$ wet mount

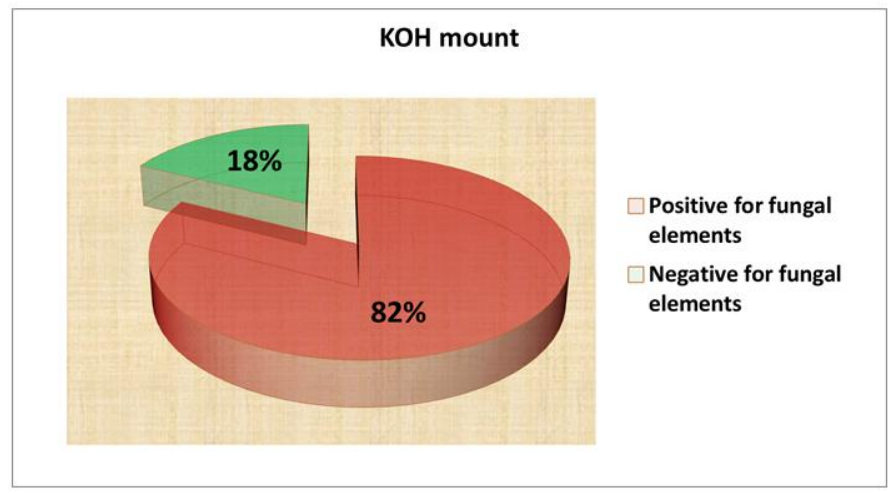


Diagram.2 Pie Diagram Showing Percentage of Culture Positivity

\section{Culture positivity}

\section{Culture positive $\quad$ Culture sterile}

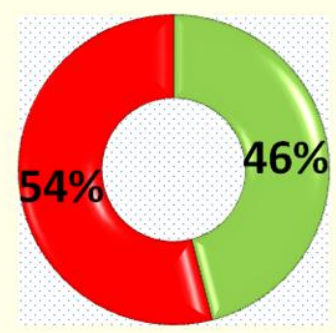

Diagram.3 Bar Diagram Showing Fungal Isolates Obtained from Corneal Scrapings

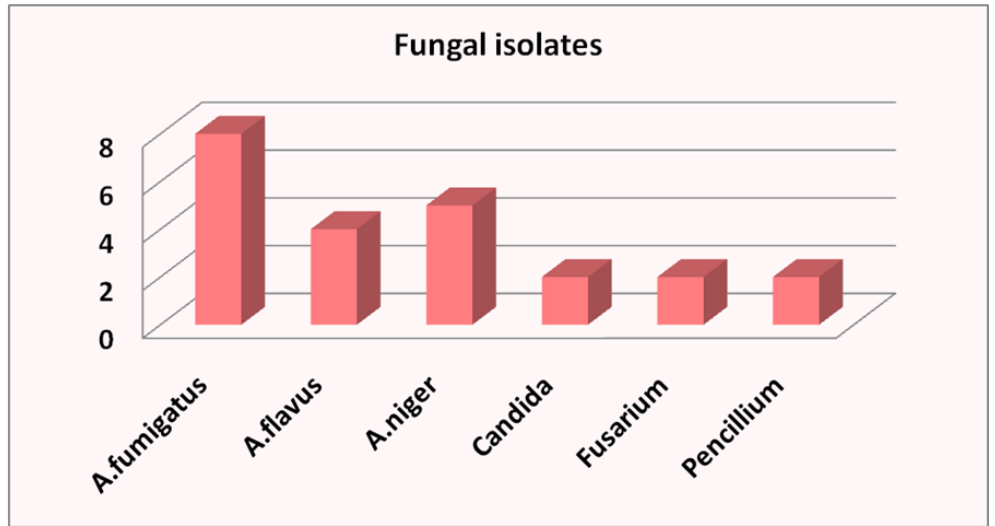

Diagram.4 Bar Diagram Showing Age Distribution Pattern of Keratomycosis

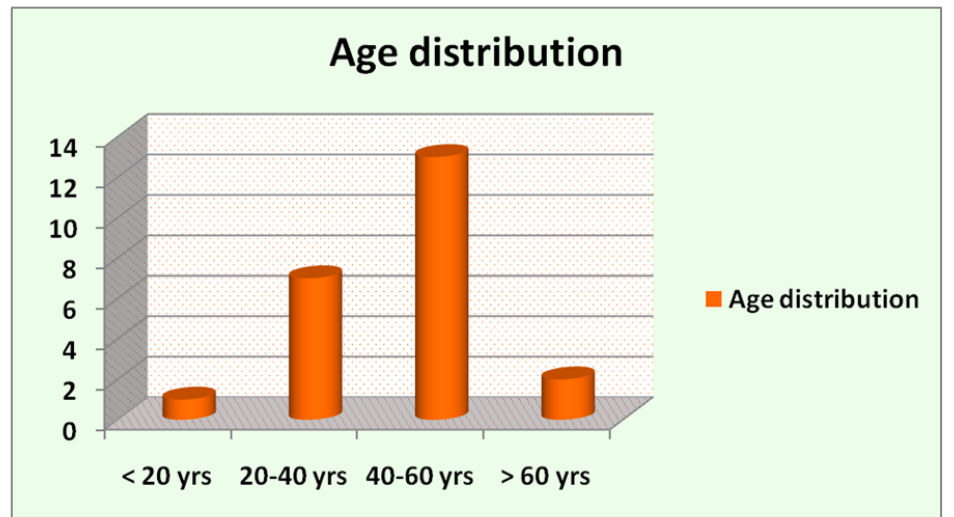


Diagram.5 Bar Diagram Showing Sex Distribution Pattern of Keratomycosis

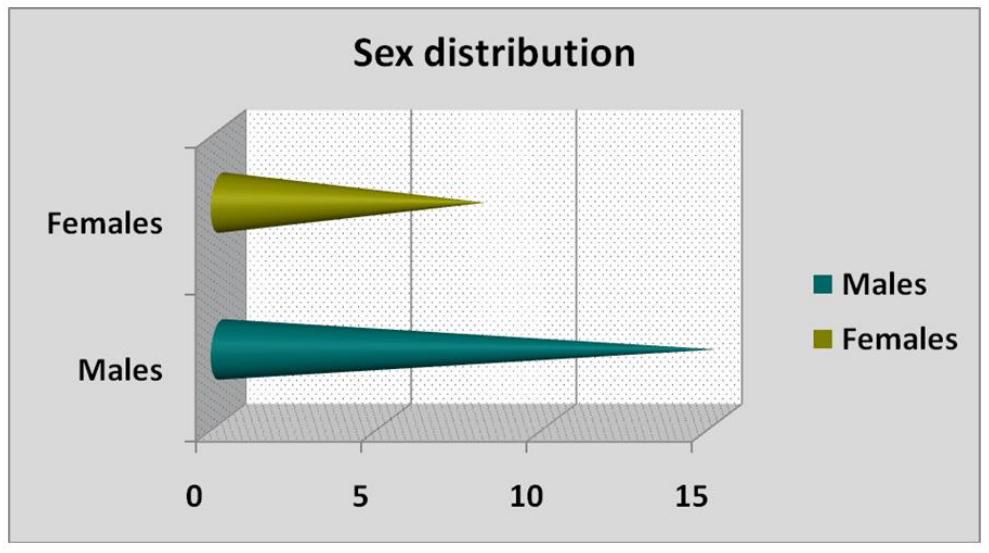

Diagram.6 Bar Diagram Showing the Impact of Occupation on Keratomycosis

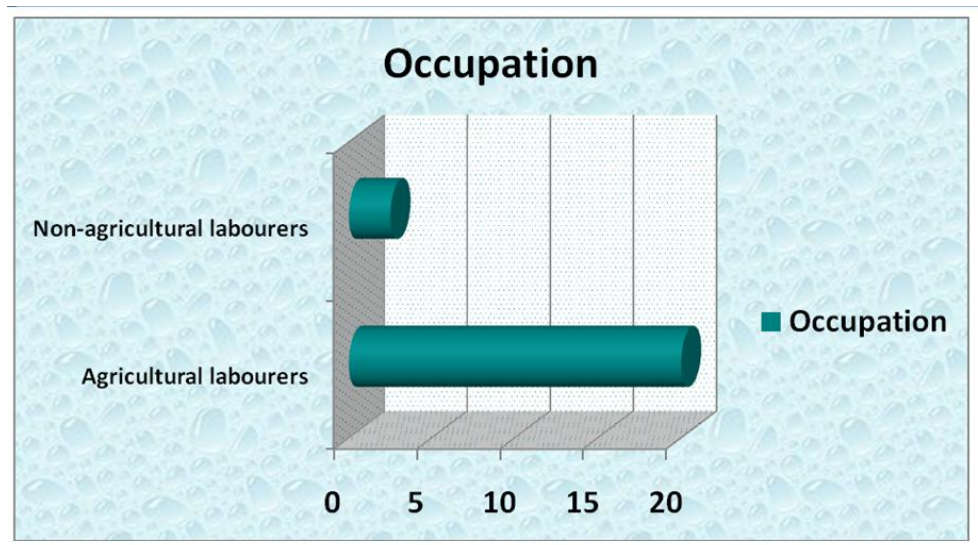

Diagram.7 Pie Diagram Showing the Nature of Trauma Responsible Forkeratomycosis

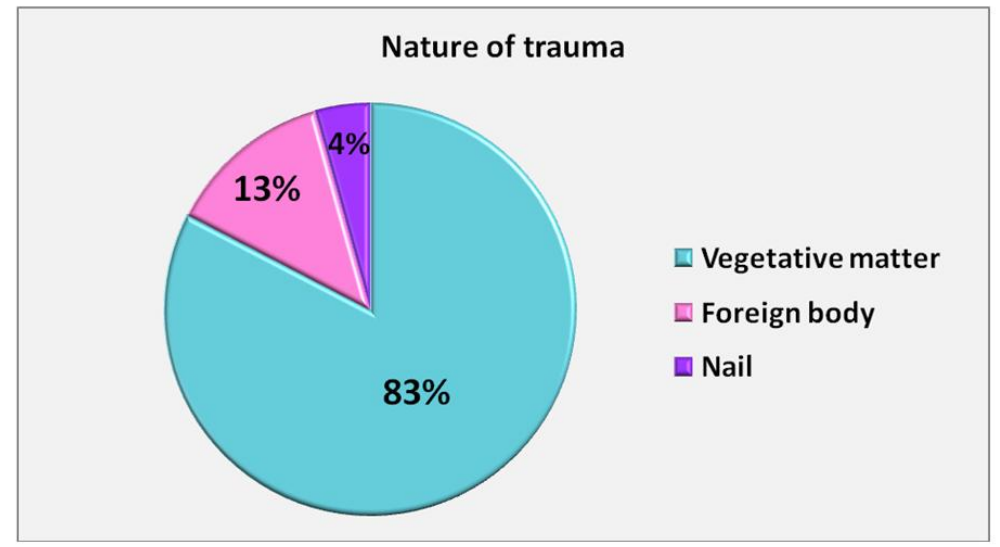

Fungal corneal ulcers were more common in agricultural labourers $(86.9 \%)$ when compared to non-agricultural labourers (Diagram 6). This might be because of more chances of exposure to vegetative matter in farmers than others. Corneal injury appears to be the most important predisposing factor followed by diabetes mellitus. Vegetative matter (83\%), 
followed by foreign body (13\%) is the most common agent responsible for trauma (Diagram 7).

Antifungal susceptibility testing was done as per CLSI M44-A2 guidelines for Candida and CLSI M51-A for non-dermatophytic filamentous fungi on Mueller Hinton agar

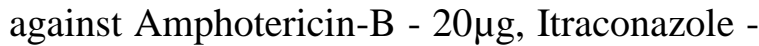

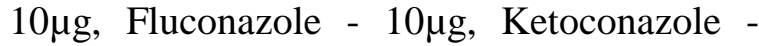
$10 \mu \mathrm{g}$, Clotrimazole - $10 \mu \mathrm{g}$ and Nystatin 100units/disc (Table 1).

In the present study, males are more commonly affected than that of females. Similar gender predilection was shown by Joanne W.Ho, et al., (2016); Xie L, et al., (2006); Iyer SA' et al. (2006); Chowdhary A, et al. (2005) and Bharathi MJ, et al. (2003).

A large proportion of the patients affected with keratomycosis in the present study were middle-aged adults, and most of them were farmers. Ocular trauma with vegetative matter was the most important risk factor. Similar findings were observed by Wang L, et al. (2009); Joanne W. Ho, et al. (2016); Xie L, et al. (2006); Iyer SA et al. (2006); Chowdhary A, et al. (2005) and Bharathi MJ, et al. (2003).

In the present study, filamentous fungi were the most common causative pathogens. Similar findings were observed byJoanne W. Ho, et al. (2016) and Srinivasan M (2004). Aspergillus spp. is the most common isolate of the study. This finding is consistent with that of Chowdhary A, et al. (2005).

In conclusion, Fungal keratitis is often a severe disease in which diagnosis can be challenging, the response to medical treatment is slow, and the clinical outcome poor. Corneal perforation is 5 to 6 times more likely with fungal keratitis than it is with bacterial keratitis (Lisa et al., 2011). Because of serious consequences of infectious keratitis, it is important to know the exact aetiology of corneal ulcer to institute appropriate therapy in time. Laboratory confirmation should be undertaken and fungal infection should be ruled out before prescribing corticosteroids and antibacterial antibiotics (Saha and Das, 2006).

\section{References}

Bharathi, M.J., Ramakrishnan, R., Meenakshi, R., Padmavathy, S., Shivakumar, C., Srinivasan, M. 2007. Microbial keratitis in South India: influence of risk factors, climate, and geographical variation. Ophthalmic Epidemiol., 14(2): 61-9.

Bharathi, M.J., Ramakrishnan, R., Vasu, S., Meenakshi, R., Palaniappan, R. 2003. Epidemiological characteristics and laboratory diagnosis of fungal keratitis. A three-year study. Indian J. Ophthalmol., 51(4): 315-21.

Chowdhary, A., Singh, K. 2005. Spectrum of fungal keratitis in North India. Cornea, 24(1): 8-15.

diBisceglie, A.M., Carmichael, T.R. 1987. Factors predisposing to central corneal ulceration in a developing population. $S$. Afr. Med. J., 71(12): 769-70.

Dóczi, I., Gyetvai, T., Kredics, L., Nagy, E. 2004. Involvement of Fusarium spp. in fungal keratitis. Clin. Microbiol. Infect., 10(9): 773-6.

Iyer, S.A., Tuli, S.S., Wagoner, R.C. 2006. Fungal keratitis: emerging trends and treatment outcomes. Eye Contact Lens, 32(6): 267-71.

Joanne, W., Ho, Mark, M., Fernandez, Rachelle, A., Rebong, Alan, N., Carlson, Terry Kim, Natalie, A., Afshari. 2016. Microbiological profiles of fungal keratitis: a 10-year study at a tertiary referral center. J. Ophthalmic Inflamm Infect., 6: 5.

Laspina, F., Samudio, M., Cibils, D., Ta, C.N., Fariña, N., Sanabria, R., Klauss, V., Miño de Kaspar, H. 2004. Epidemiological characteristics of microbiological results on patients with infectious corneal ulcers: a 13-year survey in Paraguay. Graefes Arch. Clin. Exp. Ophthalmol., 242(3): 204-9. 
Liesegang, T.J., Forster, R.K. 1980. Spectrum of microbial keratitis in South Florida. Am. J. Ophthalmol., 90(1): 38-47.

Lisa, J., Keay, Emily, W., Gower, Alfonso Iovieno, Rafael, A., Oechsler, Eduardo, C., Alfonso, M.D., Alice Matoba, Kathryn Colby, Sonal, S., Tuli, Kristin Hammersmith, Dwight Cavanagh, Salena, M., Lee, John Irvine, R., Doyle Stulting, Thomas, F., Maugerand Oliver, D., Schein. 2011. Clinical and Microbiological Characteristics of Fungal Keratitis in the United States, 2001-2007: A Multicenter Study. Ophthalmol., 118(5): 920-926.

Saha, R., Das, S. 2006. Mycological profile of infectious Keratitis from Delhi. Indian J. Med. Res., 123(2): 159-64.

Srinivasan, M. 2004. Fungal keratitis. Curr. Opin. Ophthalmol., 15(4): 321-7.

Tuft, S.J., Tullo, A.B. 2009. Fungal keratitis in the United Kingdom 2003-2005. Eye (Lond), 23(6): 1308-13.
Upadhyay, M.P., Karmacharya, P.C., Koirala, S., Tuladhar, N.R., Bryan, L.E., Smolin, G., Whitcher, J.P. 1991. Epidemiologic characteristics, predisposing factors, and etiologic diagnosis of corneal ulceration in Nepal. Am. J. Ophthalmol., 111(1): 92-9.

Wang, L., Sun, S., Jing, Y., Han, L., Zhang, H., Yue, J. 2009. Spectrum of fungal keratitis in central China. Clin. Experiment Ophthalmol., 37(8): 763-71.

Wong, T.Y., Fong, K.S., Tan, D.T. 1997. Clinical and microbial spectrum of fungal keratitis in Singapore: a 5-year retrospective study. Int Ophthalmol., 21(3): 127-30.

Xie, L., Zhong, W., Shi, W., Sun, S. 2006. Spectrum of fungal keratitis in north China. Ophthalmol., 113(11): 1943-8.

\section{How to cite this article:}

Venkata Hemalatha Neeli and T. Parvathi. 2016. Study of Keratomycosis in a Tertiary Care Hospital in Visakhapatnam, India. Int.J.Curr.Microbiol.App.Sci.5(4): 351-359. doi: http://dx.doi.org/10.20546/ijcmas.2016.504.042 